\title{
Are Cross Border Acquisitions More Profitable, or Do They Make Profit More Persistent, than Domestic Acquisitions? UK Evidence
}

\author{
Abimbola Adedeji ${ }^{1}$, Maha D. Ayoush ${ }^{2}$ \\ ${ }^{1}$ Department of Finance, Birmingham Business School, University of Birmingham, Edgbaston, Birmingham B15 \\ 2TT, UK \\ ${ }^{2}$ Department of Accounting, Faculty of Economics and Administrative Sciences, Al-Zaytoonah University of \\ Jordan, 130 Amman 11733, Jordan \\ Correspondence: Abimbola Adedeji, Department of Finance, Birmingham Business School, University of \\ Birmingham, Edgbaston, Birmingham B15 2TT, UK. E-mail: T.A.Adedeji@bham.ac.uk
}

Received: March 6, 2017

doi:10.5539/ibr.v10n6p178

\author{
Accepted: May 12, 2017 \\ Online Published: May 22, 2017 \\ URL: https://doi.org/10.5539/ibr.v10n6p178
}

\begin{abstract}
Cross border acquisitions were relatively more popular than domestic acquisitions in the UK and many other countries during late 1990s and the beginning of this century (Martynova and Renneboog, 2008, among others). Apart from attributing it to the wave of globalisation that occurred at the time, hardly any other reason has been given for this phenomenon in the literature. In this paper, we check whether cross border acquisitions were more profitable than domestic acquisitions to bidders, or whether cross border acquisitions made the profitability of bidders to be more persistent than domestic acquisitions, during the period referred to above. Evidence observed from a sample of 199 cross border, and 174 domestic, acquisitions made by firms in the UK during 1996-2003 shows that the cross border acquisitions were significantly less profitable, and that they did not make the profitability of the bidders significantly more persistent, than the domestic acquisitions. These indications are similar to those of the US evidence reported by Moeller and Schlingemann (2005) and raise questions about why cross border acquisitions were relatively more popular than domestic acquisitions during the period referred to above.
\end{abstract}

Keywords: profitability, persistence of profitability, domestic acquisitions and cross border acquisitions

\section{JEL Classifi cation: G34}

\section{Introduction}

Evidence reported by previous studies shows that cross border acquisitions were relatively more popular than domestic acquisitions in the UK and other parts of the world during late 1990s and the beginning of this century (Goergen and Renneboog, 2004; Moeller and Schlingemann, 2005 - hereafter, M\&S; Conn, et al, 2005; and Martynova and Renneboog, 2008; among others). Whilst the evidence is not surprising, because this was a period of rapid globalisation, it makes one to wonder whether there was any rational economic reason behind this phenomenon. One such reason could be that cross border acquisitions were more profitable than domestic acquisitions to bidders and another could be that cross border acquisitions made the profitability of bidders to be relatively more stable than domestic acquisitions. A way to find out whether cross border acquisitions had either, or both, of these benefits over domestic acquisitions during the period referred to above is to compare the impacts of the two types of acquisitions on the profitability, and stability of the profitability, of bidders during the period. In the context of mergers and acquisitions, the impact of acquisitions on the stability of the profitability of bidders is usually measured by the "persistence" of the profitability of bidders around the time of the acquisitions. "Persistence" of the profitability of bidders is the extent to which the level of profitability of bidders after they make acquisitions is related to their level of profitability before they make the acquisitions (Healy, Palepu and Ruback, 1992).

M\&S have compared the impacts of cross border and domestic acquisitions on the profitability, and the persistence of the profitability, of merged firms (that is, acquiring and target firms combined) in the US during 1985-95. They find that the firms were significantly less profitable when they acquired cross border targets than when they acquired domestic targets and that there is no significant difference between the impacts of the two types of acquisitions on the persistence of the profitability of the firms ${ }^{1}$. 
The study reported in this paper compares the impacts of cross border and domestic acquisitions on the profitability, and persistence of the profitability, of firms in the UK which made acquisitions during late 1990s and the early part of this century. There are two reasons for the study. One of them is that since the evidence reported by $\mathrm{M} \& \mathrm{~S}$ is about the difference between the impacts of cross border and domestic acquisitions on the profitability, and persistence of the profitability, of merged firms, it may not apply to bidders or acquirers alone, because previous studies have shown that the impacts of acquisitions on the market returns on the shares of bidders and targets are usually different from each other (Tuch and O'Sullivan, 2007; Ismail, et al, 2011). The results of the studies imply that any statistically significant difference observed between the impacts of cross border and domestic acquisitions on the profitability of merged firms may not apply to bidders, or targets, alone.

There is also empirical evidence that cross border acquisitions improve operating performance of targets (Bertrand and Zitouna, 2005 and Fraser and Zhang, 2009). But there is hardly any rigorous empirical evidence in the literature about the difference between the impacts of cross border and domestic acquisitions on the profitability, and persistence of the profitability, of bidders alone. This issue is important because many firms that are involved in cross border deals probably just want to make acquisitions rather than be involved in mergers. Information about the difference between the impacts of cross border and domestic acquisitions on the profitability, and persistence of the profitability, of bidders alone will be useful to them, if they want to choose between acquiring cross border targets and domestic targets.

The other reason for the study reported in this paper is that the difference between the impacts of cross border and domestic acquisitions on the profitability, and persistence of the profitability, of bidders may vary from sample to sample. Consequently, any view about the difference between the impacts of cross border and domestic acquisitions on the profitability, and persistence of the profitability, of bidders in the UK should be based on UK evidence, because the evidence reported by M\&S, referred to above, may not apply to the UK.

We do not know any other study in the literature which has rigorously compared the impacts of cross border and domestic acquisitions on the profitability, and persistence of the profitability, of either merged firms, or bidders alone, than that of M\&S. So, there is a gap in the literature. The contribution of this paper is that it reports the UK evidence on this issue and, hence, bridges part of the gap. We focus on the UK because the country was the hub for mergers and acquisitions, outside the US, during our study period. The number, and value, of cross border mergers and acquisitions made by UK firms during the period exceeded those of the cross border mergers and acquisitions made by firms in any other country in Europe and were next only to those made by firms in the US (Sudarsanam, 2010 and Ayoush, 2011).

The sample used to generate the evidence contains 373 acquisitions made by firms listed on the London Stock Exchange during 1996-2003. All bidders, and 174 (or approximately 46.6\%) of the targets, were from the UK. The other targets (199, or approximately $53.4 \%$ of the targets) were cross border acquisitions made by the UK bidders from the US, other European countries than the UK and the rest of the world (Ayoush, 2011). The evidence gives similar indications to the one reported by M\&S. Among other things, the evidence shows that the profitability of the bidders in the UK was significantly lower when they acquired cross border targets, than when they acquired domestic targets, and that there is no significant difference between the impacts of the two types of acquisitions on the persistence of the profitability of the bidders. These indications of the evidence are robust to different definition and measurement of the profitability of the bidders. Therefore, it appears that the greater popularity of cross border acquisitions over domestic acquisitions in the UK during late 1990s and the beginning of this century was not because cross border acquisitions were more profitable, or made the profitability of bidders to be more stable, than domestic acquisitions.

The rest of the paper is organised as follows: the reasons why the impacts of cross border acquisitions on the profitability, and persistence of the profitability, of bidders may be different from those of domestic acquisitions, and why the difference between the impacts of the two types of acquisitions may vary from sample to sample, are explained in the next section. This is followed by the description of the methodology used in the study. The results obtained are presented in the penultimate section and the paper is concluded in the final section.

\section{Why the Impacts of Cross Border and Domestic Acquisitions may be Different from Each Other and Why the Difference between the Two may Vary from Sample to Sample}

There are various market imperfections that can make the prices of finished products and raw materials, as well as labour costs, tax charges, other operating expenses and financing costs, to be unequal across countries (Eitemann, Stonehill and Moffett, 2016). The imperfections can cause differences between the profitability of cross border and domestic acquisitions to bidders. A-priori, it is difficult to tell how the imperfections will make the profitability of cross border and domestic acquisitions to differ because their impacts will depend on the 
types of imperfections that they are, the amount of each of them and how each of them will affect the profits that bidders will realise on a particular set of cross border and domestic acquisitions. Consequently, the difference between the impacts of cross border and domestic acquisitions on the profitability of bidders may vary from sample to sample.

Also, international diversification theory suggests that international diversification (such as a cross border acquisition) may reduce the volatility of the profitability of firms (Hughes, Logue and Sweeney, 1975) for two reasons. One of them is that the economic cycles of the countries that bidders are may be opposite to those of the countries that their cross border targets are. Whenever that is so, the profitability of each bidder and its cross border target combined will be more stable (that is, be more persistent) than the profitability of the same bidder combined with a domestic target that is similar to the cross border target. The other reason is that the cross border targets may be in countries which are financially less risky than those of their bidders. Again, whenever that is so, the profitability of each bidder and its cross border target combined will be more stable than that of the same bidder combined with a domestic target that is similar to the cross border target.

The explanations stated above are based on portfolio theory. The theory suggests that if:

$\sigma_{\mathrm{BT}}=$ standard deviation of the profitability of a bidder and a target combined after an acquisition;

$\sigma_{\mathrm{B}}=$ standard deviation of the profitability of the bidder before the acquisition;

$\sigma_{\mathrm{T}}=$ standard deviation of the profitability of the target before the acquisition;

$\rho_{\mathrm{BT}}=$ correlation between the profitability of the bidder and the target;

$\mathrm{w}_{\mathrm{B}}=$ weight of the contribution of the bidder to the profitability of the bidder and the target combined after the acquisition; and

$\mathrm{w}_{\mathrm{T}}=$ weight of the contribution of the target to the profitability of the bidder and the target combined after the acquisition;

then,

$$
\sigma_{B T}=\sqrt{W_{B}^{2} \sigma_{B}^{2}+W_{T}^{2} \sigma_{T}^{2}+2 W_{B} W_{T} \rho_{B T} \sigma_{B} \sigma_{T}}
$$

Therefore, if the economic cycles of the countries of the bidders are opposite to those of the countries of their targets, then $\rho_{\mathrm{BT}}$ in equation (1) will be negative. Since the values of all other variables in the equation will be positive, the negative value of $\rho_{\mathrm{BT}}$ will make the whole of $2 \mathrm{~W}_{\mathrm{B}} \mathrm{W}_{\mathrm{T}} \rho_{\mathrm{BT}} \sigma_{\mathrm{B}} \sigma_{\mathrm{T}}$ to be negative and reduce the value of $\sigma_{\mathrm{BT}}$. Similarly, if $\sigma_{\mathrm{B}}>\sigma_{\mathrm{T}}$ and part of the fund previously invested in the bidder is transferred to a target located in a country which is financially less risky than the country where the bidder is, the value of $\sigma_{\mathrm{BT}}$ will reduce, all things being equal ${ }^{2}$.

However, very little is known about whether firms usually acquire cross border targets that are in countries which have opposite economic cycles to their own, or in countries which are financially less risky than their own, because there is hardly any direct empirical evidence on this issue in the literature. The empirical evidence that is in the literature is about the impacts of foreign direct investment (FDI) made by firms on their total risk and market beta values, among others. The evidence indicates that firms make FDI in countries which are financially less risky, as well as in countries which are financially more risky, than their own, and that when firms make FDI in countries which are financially less risky than their own, their total risk and market beta values decrease. But when firms make FDI in countries which are financially more risky than their own, their total risk and market beta values increase (Kwok and Reeb, 2000). Even though the evidence is about FDI, its indication is consistent with the explanation stated above about why the impacts of cross border and domestic acquisitions on the persistence of the profitability of acquirers may differ. So, the evidence appears to be relevant to cross border acquisitions as well.

From the point of view of our study, the most important indication of the evidence referred to above is that firms may acquire cross border targets from various countries, regardless of market imperfections and the nature of the relationships between the economic cycles of their own countries and the countries of their targets, and regardless of whether the countries of their targets are financially less, or more, risky than their own. This implies that the difference between the impacts of cross border and domestic acquisitions on the profitability, and persistence of the profitability, of bidders may vary from sample to sample. Whether this variation occurs or not depends on the relationships between the economic cycles and the levels of financial risk in the countries of the bidders and the cross border targets in a study sample.

Since there is no direct empirical information on this issue in the literature, it will be useful to know whether there are significant differences between the impacts of cross border and domestic acquisitions on the 
profitability, and persistence of the profitability, of bidders in different countries. As stated earlier, it appears that only the US evidence reported by M\&S is in the literature before this paper. It will be useful to have evidence from other countries for information and comparison.

\section{Methodology}

We measure the profitability of a bidder in a year by the ratio of its 'pure' operating cash flow to its total assets in the year (that is, (EBITDA $-\Delta \mathrm{WC}$ )/Total Assets), where EBITDA is earnings before interest, tax, depreciation and amortisation and $\triangle \mathrm{WC}$ is change in working capital. This measure is used in order to control the potential bias that accounting policies of bidders may cause to their profitability in the year of acquisition or some other years (Lawson, 1985 and Powell and Stark, 2005). As in Healy, et al (1992) and M\&S, we adjust the value of the measure for industry median in each year in order to control the potential effect of industry on it. We also control the potential joint effects of industry, pre-acquisition size and performance of bidders on their post-acquisition level of profitability by deducting the median value of the level of profitability of a firm that is comparable with each bidder in industry, size and pre-acquisition level of profitability from the value of the variable for the bidder in each year after the acquisition.

In order to be able to assess the effect of industry alone, and the joint effects of industry, size and pre-acquisition performance together, on the post-acquisition level of profitability of the bidders, we create two variables. One of them is called industry-adjusted level of profitability $\left(\mathrm{PR}_{\text {ind-adji,t }}\right)$ and the other is called industry-size-and-pre-acquisition-adjusted level of profitability $\left(\mathrm{PR}_{\text {ind,size,perf-adji, }}\right)$. The values of the variables are calculated as follows:

$$
\begin{array}{r}
P R_{\text {ind-adji,t }}=P R_{\text {Bidderi,t }}-P R_{\text {ind-median in year } t} \\
P R_{\text {ind,size,perf-adji,t }}=P R_{\text {Bidderi,t }}-P R_{\text {benchmark firm in yeart }}
\end{array}
$$

where,

$$
\begin{aligned}
& \mathrm{PR}_{\text {ind-adji, }}=\text { industry-adjusted level of profitability of bidder } \mathrm{i} \text { in year } \mathrm{t} \text {; } \\
& \mathrm{PR}_{\mathrm{Bidderi,t}}=\text { raw level of profitability of bidder } \mathrm{i} \text { in year } \mathrm{t} \text {; } \\
& \mathrm{PR}_{\text {ind,size,perf-adji,t }}=\text { industry-size-and-pre-acquisition-performance-adjusted level of profitability of bidder } \mathrm{i} \text { in } \\
& \text { year } \mathrm{t} \text {; } \\
& \mathrm{PR}_{\text {ind-median in year } \mathrm{t}}=\text { industry median level of profitability in year } \mathrm{t} \text {; and } \\
& \mathrm{PR}_{\text {benchmark fim in yeart }}=\text { level of profitability of the benchmark firm (that is, a firm in the same industry, and } \\
& \text { with a similar size to the bidder, in the pre-acquisition year which is not involved in any acquisition) in } \\
& \text { year } \mathrm{t} \text {. }
\end{aligned}
$$

Following previous studies (e.g., Healy, et al, 1992; Kumar and Rajib, 2007), we calculate the value of each of the variables described in equations (2) and (3) above for 1,2 and 3 years before, and after, each acquisition that is, for $\mathrm{t}=-3,-2,-1,1,2$ and 3 respectively. Year 0 (that is, the year of acquisition) is excluded in order to avoid the noise that may be in the data of that year as a result of accounting differences between the bidders and targets and one-time acquisition costs incurred in the year which may distort the result of the comparison of the level of profitability of the bidders in that year with their level(s) of profitability in the other years. Then, the median value of each of the variables for the three years before each acquisition (that is, for $t=-3,-2$ and -1 ) is determined and called pre-acquisition level of profitability, PRpre. Also, for each acquisition, the median value of each of the variables for the three years after the acquisition (that is, for $t=1,2$ and 3 ) is determined and called post-acquisition level of profitability, PRpost.

In order to avoid survival bias, bidders which existed for less than three years before they acquired their targets, and those which ceased to exist in less than three years after they acquired their targets, are included in our study sample. However, when data are available for only two years, the average value of each of the variables over the two years before, or after, the acquisition concerned is used as the PRpre, or PRpost, as appropriate. Also, when data are available for only a year before, or after, an acquisition, the value of each of the variables for the year before, or after, the acquisition is used as the PRpre or PRpost. Then, we use ordinary least squares regression technique to estimate the following equations: 


$$
\begin{gathered}
\text { POCFIND }= \\
\propto_{0}+\propto_{1} \text { PRCFIND }+\propto_{2} C B+\propto_{3} * C B * \text { PRCFIND }+\propto_{4} \text { CP }+\propto_{5} \text { INDR }+\propto_{6} \text { RELSIZE }+\varepsilon
\end{gathered}
$$

$$
\begin{gathered}
\text { POCFISP }= \\
\beta_{0}+\beta_{1} \text { PRCFISP }+\beta_{2} C B+\beta_{3} * C B * \text { PRCFISP }+\beta_{4} C P+\beta_{5} I N D R+\beta_{6} \text { RELSIZE }+\Phi
\end{gathered}
$$

where,

POCFIND = industry-adjusted post-acquisition cash flow measure of the level of profitability of a bidder;

POCFISP = industry-size-pre-acquisition-performance-adjusted cash flow measure of the level of profitability of a bidder, after the acquisition;

PRCFIND = industry-adjusted pre-acquisition cash flow measure of the level of profitability of a bidder;

PRCFISP = industry-size-pre-acquisition-performance-adjusted cash flow measure of the level of profitability of a bidder, before the acquisition;

$\mathrm{CB}=$ a dummy variable allocated a value of 1 for cross border acquisitions and 0 for domestic acquisitions;

$\mathrm{CP}=$ a dummy variable allocated a value of 1 for acquisitions paid for entirely in cash and 0 for all others;

INDR $=$ a dummy variable allocated a value of 1 for acquisitions of targets that are in the same industry with their bidders and 0 for others;

RELSIZE = relative size of a target to its bidder, represented by the ratio of the deal value to the market value of the equity of a bidder; and

$\varepsilon$ and $\Phi$ are error terms.

$\alpha_{1}$ and $\beta_{1}$ in equations (4) and (5) are measures of the impact of the domestic acquisitions on the persistence of the profitability of the bidders (hereafter, domestic persistence) in our sample. Similarly, the sum of $\alpha_{1}$ and $\alpha_{3}$ in equation (4), and the sum of $\beta_{1}$ and $\beta_{3}$ in equation (5), are measures of the impact of the cross border acquisitions on the persistence of the profitability of the bidders in our sample (hereafter, cross border persistence). So, if $\alpha_{3}$ is positive and statistically significant in the estimate of equation (4), and $\beta_{3}$ is positive and statistically significant in the estimate of equation (5), then the cross border persistence of the profitability of the bidders in our sample is significantly higher than the domestic persistence of their profitability, and vice versa.

We include some dummy variables in equations (4) and (5) to control the potential impacts of certain deal characteristics on the profitability of the bidders, which may affect the difference between the cross border and domestic persistence of their profitability. The deal characteristics that the dummy variables are used to control their potential impacts are method of payment (specifically, cash payment, CP), industrial relatedness of each target to its acquirer (INDR) and the relative size of each target to its bidder's (RELSIZE).

Acquisitions which are paid for entirely in cash may be more profitable than those which are paid for entirely with shares, or with a mixture of cash, shares and other types of securities. That's because bidders usually pay for acquisitions entirely in cash when they are sure of realising a profit on them, and often pay entirely with shares, or with a mixture of cash, shares and other types of securities, for acquisitions which they are not sure of realising a profit on (Linn and Switzer, 2001 and Tuch and O'Sullivan, 2007). If the acquisitions in our sample were paid for in this way, then variable $\mathrm{CP}$ should have a significant positive coefficient in the estimates of equations (4) and (5). Similarly, acquisitions of targets that are in the same industry, or line of business, with their bidders are more likely to generate synergies and profit to the bidders than acquisitions of targets that are not (Singh and Montgomery, 1987; Tuch and O'Sullivan, 2007). If our sample supports this suggestion, then dummy variable INDR should have a significant positive coefficient in the estimates of equations (4) and (5). Also, acquisitions of larger targets may be more profitable than acquisitions of smaller targets because competition for larger targets is usually less intense than competition for smaller ones. Hence, acquirers usually pay relatively less for larger targets, and consequently realise relatively more profit on them, than on smaller targets (Bruner, 2002 and Tuch and O'Sullivan, 2007). If this suggestion applies to our sample, then the coefficient of the RELSIZE variable should be positive and statistically significant in the estimates of equations (4) and (5).

$\alpha_{0}$ and $\beta_{0}$ (that is, the constants) measure the impacts of the cross border and domestic acquisitions on the profitability of the bidders, after controlling the effects of the other factors. Therefore, a negative and statistically 
significant value of each of them will mean that industry-adjusted (or industry-size-pre-acquisition-performance-adjusted) profitability of the bidders reduced significantly after acquisitions, and vice versa. If the profitability of the bidders is significantly persistent over the acquisition period, then the estimates of $\alpha_{1}$ and $\beta_{1}$ should be positive and statistically significant. The more persistent the profitability is over the period, the greater will be the estimated values of $\alpha_{1}$ and $\beta_{1}$. Also, $\alpha_{2}$ and $\beta_{2}$ measure the difference between the impacts of the cross border and domestic acquisitions on the profitability of the bidders. If each of them is positive and statistically significant, then the impact of the cross border acquisitions on the profitability of the bidders is significantly more than that of the domestic acquisitions, and vice versa. The estimates of $\alpha_{2}, \beta_{2}$ and their statistical significance, are one of the two issues that the study reported in this paper is about.

$\alpha_{3}$ and $\beta_{3}$ measure the difference between the cross border and domestic persistence of the profitability of the bidders. If there was no volatility in the profitability of a bidder from the period before, to the period after, it acquired a target, then its POCFIND and PRCFIND in equation (4), and POCFISP and PRCFISP in equation (5), should be the same. If this was so for all acquisitions in our sample, then the estimates of $\alpha_{3}$ and $\beta_{3}$ should be 1 each, and those of $\alpha_{0}$ and $\beta_{0}$ should be 0 each. But profitability of firms usually varies over time, mainly because of the volatility of their revenues. Therefore, if the profitability of the bidders in our sample was relatively more stable when they acquired cross border targets than when they acquired domestic targets, then the difference between their POCFIND and PRCFIND in equation (4), and POCFISP and PRCFISP in equation (5), should be smaller when they acquired cross border targets than when they acquired domestic targets. Consequently, estimates of $\alpha_{3}$ and $\beta_{3}$ should be positive and statistically significant. Negative estimates of $\alpha_{3}$ and $\beta_{3}$ imply the opposite. That is, they imply that the profitability of the bidders was more volatile when they acquired cross border targets than when they acquired domestic targets. The sign and statistical significance of the estimates of $\alpha_{3}$ and $\beta_{3}$ are the other issue that the study reported in this paper is about. Finally, $\alpha_{4}-\alpha_{6}$ in equation (4), and $\beta_{4^{-}}-\beta_{6}$ in equation (5), represent the impacts of the deal characteristics that they are associated with on the profitability of the bidders ${ }^{3}$.

The data used for the study are obtained from two sources. Names of firms in the UK which acquired other firms in the UK and overseas are identified and collected manually from Acquisitions Monthly, a magazine published by Thomson Financial Limited. We were able to get the magazine from only January 1996 to December 2003. That is why our sample consists of only cross border and domestic acquisitions that were made by firms listed on the London Stock Exchange during this period. All the other data that we use are obtained from Datastream. Only firms that have all the data required for the study for at least one year before, and one year after, they were involved in an acquisition deal are included in the sample. Application of this selection criterion gives us 199 cross border acquisitions and 174 domestic acquisitions, making a total of 373 acquisitions. Table 1 below provides further information about the composition of the sample.

Among other things, the statistics in Panel A of the Table show that the sample contains almost equal numbers of cross border and domestic acquisitions and that most of the acquisitions were made during 1996-2000. Also, the statistics in Panel B show that about 38\% of the acquisitions were paid for entirely in cash. More than half of the acquisitions were horizontal (that is, the bidders and targets were in the same industry or line of business) and over two-thirds of the targets were less than $10 \%$ of their bidders' sizes. Further, the summary statistics of the sample in Table 2 show that the mean and median values of POCFIND and POCFISP are small, relative to those of PRCFIND and PRCFISP, respectively, and that there is a large variation in the values of the four variables (POCFIND, POCFISP, PRCFIND and PRCFISP). The statistics also show that, in terms of relative size (RELSIZE), the majority of the targets are less than $3 \%$ of their bidders, even though some of the targets are over three times larger than their bidders. 
Table 1. Sample Composition

\begin{tabular}{|c|c|c|c|c|c|c|}
\hline \multirow[b]{2}{*}{ Description } & \multicolumn{2}{|c|}{$\begin{array}{c}\text { Cross-border } \\
\text { acquisitions }\end{array}$} & \multicolumn{2}{|c|}{ Domestic acquisitions } & \multicolumn{2}{|c|}{ Total } \\
\hline & Number & $\%$ & Number & $\%$ & Number & $\%$ \\
\hline \multicolumn{7}{|l|}{ Panel A: Distribution by year of } \\
\hline \multicolumn{7}{|l|}{ acquisition } \\
\hline 1996 & 18 & 9.05 & 21 & 12.07 & 39 & 10.46 \\
\hline 1997 & 22 & 11.06 & 26 & 14.94 & 48 & 12.87 \\
\hline 1998 & 45 & 22.61 & 50 & 28.74 & 95 & 25.47 \\
\hline 1999 & 40 & 20.10 & 36 & 20.69 & 76 & 20.38 \\
\hline 2000 & 34 & 17.09 & 18 & 10.34 & 52 & 13.94 \\
\hline 2001 & 11 & 5.53 & 8 & 4.60 & 19 & 5.09 \\
\hline 2002 & 12 & 6.03 & 5 & 2.87 & 17 & 4.56 \\
\hline 2003 & 17 & 8.54 & 10 & 5.75 & 27 & 7.24 \\
\hline Total & 199 & 100.00 & 174 & 100.00 & 373 & 100.00 \\
\hline \multirow{2}{*}{\multicolumn{7}{|c|}{$\begin{array}{l}\text { Panel B: Distribution } \\
\text { characte ristics }\end{array}$}} \\
\hline & & & & & & \\
\hline \multicolumn{7}{|l|}{ (i) Payment Method } \\
\hline All cash & 71 & 35.68 & 69 & 39.66 & 140 & 37.53 \\
\hline Mixture of cash, shares, etc. & 128 & 64.32 & 105 & 60.34 & 233 & 62.47 \\
\hline Total & 199 & 100.00 & 174 & 100.00 & 373 & 100.00 \\
\hline \multicolumn{7}{|l|}{ (ii) Industry Relatedness } \\
\hline Same industry & 92 & 46.23 & 107 & 61.49 & 199 & 53.35 \\
\hline Different industries & 107 & 53.77 & 67 & 38.51 & 174 & 46.65 \\
\hline Total & 199 & 100.00 & 174 & 100.00 & 373 & 100.00 \\
\hline \multicolumn{7}{|l|}{ (iii) Relative size of target } \\
\hline Target size $<10 \%$ of acquirer's & 144 & 72.36 & 117 & 67.24 & 261 & 69.97 \\
\hline Target size $10 \%-50 \%$ & 44 & 22.11 & 48 & 27.59 & 92 & 24.67 \\
\hline Target size $>50 \%$ & 11 & 5.53 & 9 & 5.17 & 20 & 5.36 \\
\hline Total & 199 & 100.00 & 174 & 100.00 & 373 & 100.00 \\
\hline
\end{tabular}

\section{Results}

We first estimate equation (4) above. In the results obtained, which are summarised in Table $3, \alpha_{0}$ is not statistically significant, but $\alpha_{1}$ is positive and generally statistically significant, except when the difference between cross border and domestic persistence is controlled (as in estimate (4) in the Table). Also, $\alpha_{2}$ is negative and statistically significant, $\alpha_{3}$ is positive but not statistically significant, $\alpha_{4}$ is positive and statistically significant in estimate (3) but not in estimate (4), while $\alpha_{5}$ and $\alpha_{6}$ are not statistically significant in any of the estimates.

Table 2. Sample summary statistics

\begin{tabular}{lccccc}
\hline Variables & Mean & Median & Std. dev & Minimum & Maximum \\
\hline POCFIND & 0.0001 & 0.0084 & 0.1475 & -0.7726 & 0.4430 \\
POCFISP & 0.0095 & -0.0004 & 0.2559 & -0.6483 & 3.9570 \\
PRCFIND & 0.0224 & 0.0221 & 0.1517 & -1.1390 & 0.7382 \\
PRCFISP & 0.0664 & -0.0026 & 1.4089 & -1.1390 & 26.9594 \\
CB & 0.5335 & 1.0000 & 0.4995 & 0.0000 & 1.0000 \\
CP & 0.3753 & 0.0000 & 0.4849 & 0.0000 & 1.0000 \\
INDR & 0.5335 & 1.0000 & 0.4995 & 0.0000 & 1.0000 \\
RELSIZE & 0.1616 & 0.0296 & 0.3914 & 0.0002 & 3.1748 \\
\hline
\end{tabular}

Notes. This table contains the summary statistics of the sample. POCFIND is industry-adjusted post-acquisition cash flow measure of the level of profitability of the bidders; POCFISP is industry-size-pre-acquisition-performance-adjusted cash flow measure of the level of profitability of the bidders after the acquisitions; PRCFIND is industry-adjusted pre-acquisition cash flow measure of the level of profitability of the bidders; PRCFISP is industry-size-pre-acquisition-performance-adjusted cash flow measure of the level of profitability of the bidders before the acquisitions; CB is a dummy variable allocated a value of 1 for cross border acquisitions and 0 for domestic acquisitions; $\mathrm{CP}$ is a dummy variable allocated a value of 1 for acquisitions paid for entirely in cash and 0 for all others; INDR is a dummy variable allocated a value of 1 for acquisitions of targets that are in the same industry with their bidders and 0 for others; and RELSIZE is the relative size of a target to its bidder, represented by the ratio of the deal value to the market value of the equity of the bidder.

Therefore, the results show that the cross border acquisitions were less profitable than the domestic acquisitions. The difference was about 3.8\% of the total assets of the bidders ex-post acquisitions - see estimate (4) in Table 3. The results also show that there is no significant difference between the cross border and domestic persistence of the profitability of the bidders in our sample. 
Table 3. Estimates of equation (4)

\begin{tabular}{|c|c|c|c|c|}
\hline Independent variables & Estimate (1) & Estimate (2) & Estimate (3) & Estimate (4) \\
\hline \multirow[t]{2}{*}{ Constant $\left(\alpha_{0}\right)$} & -0.0055 & 0.0125 & -0.0197 & 0.0062 \\
\hline & $(0.4865)$ & $(0.2233)$ & $(0.1650)$ & $(0.6941)$ \\
\hline \multirow[t]{2}{*}{$\operatorname{PRCFIND}\left(\alpha_{1}\right)$} & $0.2532 \mathrm{a}$ & $0.2455 \mathrm{a}$ & $0.2368 \mathrm{a}$ & 0.1013 \\
\hline & $(0.0016)$ & $(0.0020)$ & $(0.0047)$ & $(0.2068)$ \\
\hline \multirow[t]{2}{*}{$\mathrm{CB}\left(\alpha_{2}\right)$} & & $-0.0335 b$ & & $-0.0378 b$ \\
\hline & & $(0.0217)$ & & $(0.0130)$ \\
\hline \multirow[t]{2}{*}{ CB*PRCFIND $\left(\alpha_{3}\right)$} & & & & 0.2163 \\
\hline & & & & $(0.1068)$ \\
\hline \multirow[t]{2}{*}{$\mathrm{CP}\left(\alpha_{4}\right)$} & & & $0.0253 \mathrm{c}$ & 0.0240 \\
\hline & & & $(0.0975)$ & $(0.1155)$ \\
\hline \multirow[t]{2}{*}{$\operatorname{INDR}\left(\alpha_{5}\right)$} & & & 0.0083 & 0.0032 \\
\hline & & & $(0.5864)$ & $(0.8301)$ \\
\hline \multirow[t]{2}{*}{$\operatorname{RELSIZE~}\left(\alpha_{6}\right)$} & & & 0.0037 & -0.0018 \\
\hline & & & $(0.7423)$ & $(0.8849)$ \\
\hline Adj. $\mathrm{R}^{2}$ & 0.0653 & 0.0756 & 0.0648 & 0.0834 \\
\hline F-statistic & $26.9928 \mathrm{a}$ & 16.2218 & 7.4449 & 6.6392 \\
\hline (p-value) & $(0.0000)$ & $(0.000)$ & $(0.0000)$ & $(0.0000)$ \\
\hline
\end{tabular}

Notes. This table contains estimates of equation (4) obtained when POCFIND is used as the dependent variable of the equation. POCFIND is industry-adjusted post-acquisition cash flow measure of the level of profitability of the bidders; PRCFIND is industry-adjusted pre-acquisition cash flow measure of the level of profitability of the bidders; $\mathrm{CB}$ is a dummy variable allocated a value of 1 for cross border acquisitions and 0 for domestic acquisitions; $\mathrm{CP}$ is a dummy variable allocated a value of 1 for acquisitions paid for entirely in cash and 0 for all others; INDR is a dummy variable allocated a value of 1 for acquisitions of targets that are in the same industry with their bidders and 0 for others; and RELSIZE is the relative size of a target to its bidder, represented by the ratio of the deal value to the market value of the equity of the bidder. $\mathrm{a}, \mathrm{b}$ and $\mathrm{c}$ indicate that the estimates are statistically significant at the $1 \%, 5 \%$ and $10 \%$ levels respectively.

4.1 Is the Result in Table 3 Affected by the Size and Pre-acquisition Performance of the Bidders Represented in Our Sample?

The potential effects of the size and pre-acquisition performance of the bidders on the measure of post-acquisition profitability that is used to obtain the results reported in Table 3 are not controlled. This could have affected the results if the bidders in our sample were larger, or more profitable, than the median firms in their industries when they acquired their targets. We check whether the results would be different if the potential effects of size, pre-acquisition performance and industry on the post-acquisition profitability of the bidders are controlled. This is done by estimating equation (5). The new set of results obtained, summarised in Table 4, is quite similar to the one in Table 3 . Therefore, the difference between the impacts of the cross border and domestic acquisitions on the profitability of the bidders shown by the results in Table 3 is not sensitive to whether only the effect of industry on the profitability of the bidders is controlled or whether the effects of size and pre-acquisition performance of the bidders are controlled as well. It is also evident that the lack of a statistically significant difference between the cross border and domestic persistence of the profitability of the bidders shown by the results in Table 3 is not sensitive to control for the effects of size and pre-acquisition performance of the acquirers.

\subsection{Sensitivity Analyses}

Most of the previous studies that assess the impact of acquisitions on the level of profitability of firms employ accrual based measure of profitability (e.g. Healy, et al, 1992 and M\&S) rather than the cash flow based measure of profitability that we use. Powell and Stark (2005) observe that the impact of acquisitions on the profitability of firms is greater when the accrual based measure of profitability is used than when the cash flow based measure is used. 
Table 4. Estimates of equation (5)

\begin{tabular}{|c|c|c|c|c|}
\hline Inde pendent variables & Estimate (1) & Estimate (2) & Estimate (3) & Estimate (4) \\
\hline Constant $\left(\beta_{0}\right)$ & -0.0004 & 0.01347 & -0.0156 & 0.0029 \\
\hline & $(0.9535)$ & (1.1654) & $(0.3308)$ & $(0.8722)$ \\
\hline $\operatorname{PRCFISP}\left(\beta_{1}\right)$ & $0.1495 \mathrm{a}$ & $0.1489 \mathrm{a}$ & $0.1499 \mathrm{a}$ & $0.1490 \mathrm{a}$ \\
\hline & $(0.0000)$ & $(0.0000)$ & $(0.0000)$ & $(0.0000)$ \\
\hline $\mathrm{CB}\left(\beta_{2}\right)$ & & $\begin{array}{c}-0.0260 \mathrm{c} \\
(0.0815)\end{array}$ & & $\begin{array}{l}-0.0265 c \\
(-0.0880)\end{array}$ \\
\hline CB*PRCFISP $\left(\beta_{3}\right)$ & & & & $\begin{array}{c}0.0931 \\
(0.4066)\end{array}$ \\
\hline $\mathrm{CP}\left(\beta_{4}\right)$ & & & $\begin{array}{l}0.0428 \mathrm{a} \\
(0.0058)\end{array}$ & $\begin{array}{c}0.0381 \mathrm{~b} \\
(0.0213)\end{array}$ \\
\hline $\operatorname{INDR}\left(\beta_{5}\right)$ & & & $\begin{array}{c}0.0011 \\
(0.9438)\end{array}$ & $\begin{array}{l}-0.0039 \\
(0.8021)\end{array}$ \\
\hline $\operatorname{RELSIZE~}\left(\beta_{6}\right)$ & & & $\begin{array}{c}-0.0096 \\
(-0.6630)\end{array}$ & $\begin{array}{l}-0.0125 \\
(0.4118)\end{array}$ \\
\hline Adj. $\mathrm{R}^{2}$ & 0.6762 & 0.6779 & 0.6806 & 0.6830 \\
\hline F-statistic & $777.99 a$ & $392.54 a$ & 199.16a & $134.57 \mathrm{a}$ \\
\hline (p-value) & $(0.0000)$ & $(0.0000)$ & $(0.0000)$ & $(0.0000)$ \\
\hline
\end{tabular}

Notes. This table contains estimates of equation (5) obtained when POCFISP is used as the dependent variable of the equation. POCFISP is industry-size-pre-acquisition-performance-adjusted cash flow measure of the level of profitability of the bidders after the acquisitions; PRCFISP is industry-size-pre-acquisition-performance-adjusted cash flow measure of the level of profitability of the bidders before the acquisitions; $\mathrm{CB}$ is a dummy variable allocated a value of 1 for cross border acquisitions and 0 for domestic acquisitions; CP is a dummy variable allocated a value of 1 for acquisitions paid for entirely in cash and 0 for all others; INDR is a dummy variable allocated a value of 1 for acquisitions of targets that are in the same industry with their bidders and 0 for others; and RELSIZE is the relative size of a target to its bidder, represented by the ratio of the deal value to the market value of the equity of the bidder. a, b and c indicate that the estimates are statistically significant at the $1 \%, 5 \%$ and $10 \%$ levels respectively.

Consequently, we assess the sensitivity of the results reported in Tables 3 and 4 above to the use of the accrual based measure of profitability by measuring profitability as EBITDA/Total Assets and using the value obtained to calculate the $\mathrm{PR}_{\text {ind-adji,t }}$ and $\mathrm{PR}_{\text {ind,size,perf-adji,t }}$ in equations (2) and (3) respectively. Subsequently, the new values of $\mathrm{PR}_{\text {ind-adji,t }}$ and $\mathrm{PR}_{\text {ind,size,perf-adji,t }}$ obtained are used to calculate the accrual based post- and pre-acquisition measures of profitability that correspond to the cash flow measures stated in equations (4) and (5), which are then employed to estimate the equations. The results obtained are quite similar to those in Tables (3) and (4) above. The results are not reported here in order to save space. Readers who are interested in them can obtain them from the corresponding author by request.

Finally, we perform variance inflation tests to check whether the lack of statistical significance of the estimates of the coefficients of some of the variables in equations (4) and (5) (such as CP, INDR and RELSIZE) is caused by multicollinearity. None of the tests results is statistically significant.

\section{Conclusions}

Therefore, we conclude that the greater popularity of cross border acquisitions than domestic acquisitions in the UK during the 1990s and the beginning of this century was not because cross border acquisitions were more profitable, or made the profitability of bidders significantly more stable, than domestic acquisitions. We also conclude that the difference between the impacts of the cross border and domestic acquisitions on the profitability of the bidders in our sample, as well as the similarity of the impacts of the two types of acquisitions on the persistence of the profitability of the bidders in our sample, are robust to control for the effects of industry, size and pre-acquisition performance of the bidders. Further, we conclude that they are robust to the use of cash flow based, and accrual based, measures of profitability too.

The conclusions stated above are similar to those of M\&S, even though the focus of their study is on the difference between the impacts of cross border and domestic acquisitions on the profitability of merged firms. However, our evidence, which shows that cross border acquisitions did not make the profitability of bidders to be significantly more persistent than domestic acquisitions during late 1990s and the beginning of this century, is new in the literature. Even though M\&S state on page 559 of their paper that the impact of cross border acquisitions is not significantly different from that of domestic acquisitions on the persistence of the profitability 
of the merged firms in their sample, they did not report their evidence.

The new evidence reported in this paper is interesting for a number of reasons. First, it is relevant to the international diversification theory which suggests that international diversification may reduce the volatility of the profitability of firms (Hughes, Logue and Sweeney, 1975). The evidence does not support the theory, but it supports the upstream-downstream hypothesis (Kwok and Reeb, 2000). The main implication of the hypothesis for our study is that there is no guarantee that the impact of the cross border acquisitions on the persistence of the profitability of the bidders in our sample will be significantly higher than that of the domestic acquisitions in the sample. Our results are consistent with this implication of the hypothesis.

Finally, from the point of view of finance theory, if the bidders in our sample had behaved rationally, then the cross border acquisitions that they made should have significantly enhanced either their profitability, or the persistence of their profitability, or both. Neither of these is evident from our results. This, therefore, raises the question of whether the bidders gained anything from their cross border acquisitions. Further studies should be undertaken to find out directly from bidders the benefits that they get from cross border acquisitions which justify making them rather than acquiring domestic targets. There is no such direct evidence in the literature at this moment.

\section{References}

Ayoush, M. D. (2011). Are cross-border mergers and acquisitions better or worse than domestic mergers and acquisitions? The UK evidence. PhD thesis submitted to the University of Birmingham in 2011.

Bertrand, O., \& Zitouna, H. (2005). Domestic versus cross-border acquisitions: Which impact on the target firms performance? Working Paper No. 647, IUI The Research Institute of Industrial Economics.

Boateng, A., Naraidoo, R., \& Uddin, M. (2011). An analysis of the inward cross-border mergers and acquisitions in the UK: A macroeconomic perspective. Journal of International Financial Management \& Accounting, 22(2), 91-113. https://doi.org/10.1111/j.1467-646X.2011.01046.x

Bruner, R. (2002). Does M\&A Pay? A survey of evidence for the decision maker. Journal of Applied Finance, 12, 48-68.

Conn, C., Cosh, A., Guest, P., \& Hughes, A. (2005). The impact of UK acquirers of domestic, cross-border, public and private acquisitions. Journal of Business Finance and Accounting, 32, 815-870. https://doi.org/10.1111/j.0306-686X.2005.00615.X

Eiteman, D. K., Stonehill, A. I., \& Moffett, M. H. (2016). Multinational Business Finance, $14^{\text {th }}$ edition, Pearson.

Fraser, D., \& Zhang, H. (2009). Mergers and long term corporate performance: evidence from cross-border bank acquisitions. Journal of Money, Credit and Banking, 41, 1503-1513. https://doi.org/10.1111/j.1538-4616.2009.00265.x

Goergen, M., \& Renneboog, L. (2004). Shareholder wealth effects of European Domestic and Cross-border Takeover Bids. European Financial Management, 10(1), 9-45. https://doi.org/10.1111/j.1468-036X.2004.00239.x

Healy, P., Palepu, K., \& Ruback, R. (1992). Does corporate performance improve after mergers? Journal of Financial Economics, 31, 135-175. https://doi.org/10.1016/0304-405X(92)90002-F

Hughes, J. S., Logue, D. E., \& Sweeney, R. J. (1975). Corporate International Diversification and Market Assigned Measures of Risk and Diversification. Journal of Financial and Quantitative Analysis, 10(4), 627-637. https://doi.org/10.2307/2330611

Ismail, T. H., Abdou, A. A., \& Annis, R. M. (2011). Review of literature linking corporate performance to mergers and acquisitions. The Review of Financial and Accounting Studies, 1, 89-104.

Kumar, B. R., \& Rajib, P. (2007). Mergers and Corporate Performance in India: An Empirical study. Decision, 34(1), 121-147.

Kwok, C. C. Y., \& Reeb, D. M. (2000). Internationalization and Firm Risk: An Upstream-Downstream Hypothesis. Journal of International Business Studies, 31, December, 611-629. https://doi.org/10.1057/palgrave.jibs.8490925

Lawson, G. (1985). The Measurement of Corporate Performance on a Cash Flow Basis: A Reply to Mr. Eggington. Accounting and Business Research, 15, 99-108. https://doi.org/10.1080/00014788.1985.9729253 
Linn, S. C., \& Switzer, J. A. (2001). Are cash acquisitions associated with better post combination operation performance than stock acquisitions? Journal of Banking and Finance, 6, 1113-1138. https://doi.org/10.1016/S0378-4266(00)00108-4

Martynova, M., \& Renneboog, L. (2008). Spillover of corporate governance standards in cross-border mergers and acquisitions. Journal of Corporate Finance, 14, 200-223. https://doi.org/10.1016/j.jcorpfin.2008.03.004

Moeller, S. B., \& Schlingemann, F. P. (2005). Global diversification and bidder gains: A comparison between cross-border and domestic acquisitions. Journal of Banking and Finance, 29, 533-564. https://doi.org/10.1016/S0378-4266(04)00047-0

Powell, R. G., \& Stark, A. W. (2005). Does operating performance increase post-takeover for UK takeovers? A comparison of performance measures and benchmarks. Journal of Corporate Finance, 11, 293-317. https://doi.org/10.1016/j.jcorpfin.2003.06.001

Reddy, K. S., Nangia, V. K., \& Agrawal, R. (2014). Farmers Fox Theory: does a country's weak regulatory system benefit both the acquirer and the target firm? Evidence from Vodafone-Hutchison deal. International Strategic Management Review, 2(1), 56-67. https://doi.org/10.1016/j.ism.2013.10.001

Singh, H., \& Montgomery, C. A. (1987). Corporate acquisition strategies and economic performance. Strategic Management Journal, 8, 377-387. https://doi.org/10.1002/smj.4250080407

Sudarsanam, S. (2010). Creating Value from Mergers and Acquisitions: The Challenges (2nd ed), Harlow: Prentice Hall.

Tuch, C., \& O'Sullivan, Noel (2007). The impact of acquisitions on firm performance: Areview of the evidence. International Journal of Management Review, 9, 141-170. https://doi.org/10.1111/j.1468-2370.2007.00206.x

\section{Notes}

1. See the result on page 559 of their paper and footnote number 29 on the same page.

2. It is very unlikely that the reduction in $\sigma \mathrm{BT}$ attributed to cross border acquisitions above can be generated by domestic acquisitions because the acquirer and the target will be in the same country and be affected by the same economic cycle. So, the fluctuation in the profitability of one will not be offset by the fluctuation in the profitability of the other in the opposite direction. Another reason why domestic acquisitions are unlikely to generate the reduction in $\sigma \mathrm{BT}$ referred to above is that firms usually acquire other firms that are either in the same industry with themselves, or in industries that are related to their own - in order to realise synergies and economies of scale. Therefore, when one domestic firm acquires another, $\sigma \mathrm{B}$ and $\sigma \mathrm{T}$ will be similar, because the acquirer and the target will be either in the same industry, or in related industries. Consequently, the values of $\sigma \mathrm{BT}$ for such acquisitions are likely to be higher than the corresponding values for the types of cross border acquisitions described above.

3. There are other factors than those that we have explicitly considered above that can cause disparities between the impacts of cross border and domestic acquisitions on the performances of bidders. Some examples of the factors are differences between the macroeconomic, political, cultural, tax and regulatory systems in the countries of the bidders and targets (see Boateng, Naraidoo and Uddin, 2011 and Reddy, Nangia and Agrawal, 2014, among others). These factors are not explicitly considered in this paper because we do not have the data for them for our study period.

\section{Copyrights}

Copyright for this article is retained by the author(s), with first publication rights granted to the journal.

This is an open-access article distributed under the terms and conditions of the Creative Commons Attribution license (http://creativecommons.org/licenses/by/4.0/). 